\title{
The effect of total quality management practices on employee performance: The moderating role of knowledge sharing
}

\author{
Nasser Abdul Ghani Al- Saffar ${ }^{\mathrm{a}}$ and Abdallah Mishael Obeidat ${ }^{b^{*}}$
}

${ }^{a}$ Qatar Ministry of Interior, Qatar

${ }^{b}$ Assistant Professor, Business Administration Department, Economic and Business Collage, JADARA University, Jordan

\begin{tabular}{l}
\hline C H R O N I C L E \\
\hline Article history: \\
Received: July 82019 \\
Received in revised format: July 9 \\
2019 \\
Accepted: August 11, 2019 \\
Available online: \\
August 12, 2019 \\
\hline Keywords: \\
TQM \\
Knowledge sharing \\
Qatar \\
Employee performance
\end{tabular}
A B S T R A C T

\begin{abstract}
This study aimed to identify the effect of Total Quality Management (TQM) practices on their dimensions on employee performance who worked for Qatar Ministry of Interior, with the moderating share of knowledge. The components of TQM include customer focus, employee participation, continuous improvement, leadership \& good vision and operations management. The study uses a quantitative research, where 280 questionnaires are collected from respondents to obtain the necessary information for testing the hypotheses of the study. Multiple regression and gradient regression are used to analyze the research data. The results indicate that TQM practices with its dimensions had effects on employee performance through knowledge sharing. The results of this study contribute to develop and implement different strategic directions that enhance the performance of employees through the adoption of TQM and the dissemination of a culture of knowledge sharing.
\end{abstract}

\section{Introduction}

The term quality is essentially an economic term that has emerged based on industrial and technological competition among advanced industrial countries to control production and gain customer confidence (Dawood, 2010; Abu Sultan, 2011; Aeeshe, 2012). They are defined as the suitability of the product to use, so the ability to deliver the best performance and the most accurate qualities (Saeed et al., 2013; Salami \& Ufoma Akpobire, 2013). According to Al-Zu'bi (2013), quality is the comprehensive specification of an entity which could be a product, individual, organized, related to ability to satisfy existing or presumed needs. Alwan (2013) defined it as the extent to which the product conforms to the specifications set, and the extent to which the customer's needs are met in the product. Al-Hariri (2016) regarded it as efficiency and efficiency. Obaid (2017) considered it as a production management strategy. Quality is a comprehensive philosophy and methodology for organizations that continuously improve their work in order to meet the customers' needs (Samurai, 2012). It is a management methodology designed to achieve long-term success by encouraging employee responses, meeting their needs, respecting values and beliefs (Li \& Houjun, 2013). Total Quality Management (TQM) is defined as: doing the work as planned properly and from the first time, as well as relying on the evaluation of the customer or the

* Corresponding author.

E-mail address: aabdullahh2000@hotmail.com (A. M. Obeidat) 
beneficiary by knowing the extent of appreciation for this work (Ali, 2010). TQM is a management philosophy that aims to continually improve product, service and process improvement by focusing on customer needs and expectations to enhance customer satisfaction and organization performance (Sadikoglu \& Olcay, 2014).

Performance is the achievement of work and must be accomplished. This is in line with the tendency of some researchers to focus on the individual's contribution for the achievement of the organization's objectives through the degree of achievement of his functions. Performance reflects the behavior measured by the individual's ability to contribute to the achievement of the objectives of the organization (Qureshi, 2011). According to Bartoli (1997) the performance is illustrated by the relationship between the following elements: results - resources - objectives that show how effective and performance is linked. Moreover, Salajegheh (2013) defines it as a standard for measuring results of organization's decisions, operations and determining rate of achievement. Malkawi et al. (2017) and Taleghani et al. (2013) note that job performance gives an indication of the organization's success in achieving its objectives and mission. Heinz identifies three elements of performance: (Al Ffaidi, 2008) First: Employee: in terms of the employee's skills, knowledge, interests, values and motivations. Second: the job: in terms of job, challenges and requirements. Third: Position: in terms of organizational environment and function, including the climate of supervision and work and abundance of resources and organizational structure and administrative systems.

The main objective of study is to improve employee performance in Ministry of Interior, Qatar to reach the expected or targeted performance and to achieve the objectives of the ministry. Al- Mahassna (2013) states that after the completion of official evaluation of employee performance, the results may show low performance levels for some employees, clear between the level of actual performance and level of expected performance of factor, in this case, the organization is concerned with search for means and procedures to improve performance and develop it through the appropriate procedures and methods, as it is the organization that determines the strengths and weaknesses from inside and it is more aware of how to develop and improve performance. The objective of improving performance can be only achieved through a comprehensive study of its levels, elements and analysis of organizational factors affecting it, as well as the search for effective methods to improve and develop these factors. The philosophy of improving performance represents a policy of modern organizations to improve and continuously develop all factors in organization influencing on employee performance (Al ffaidi, 2008).

Organizations today rely on knowledge as a major resource for their power. Organizations have gradually shifted to knowledge-based organizations because of their great importance. As this shift attracted the interest of many researchers in different fields to study the concept of knowledge and found an unlimited number of definitions of knowledge vary according to the approaches that dealt with. (Ali, 2013). Knowledge, facts, perspectives, beliefs, expectations, judgments, repetitive and experiential approaches can be processed and stored as information systems so that they can be easily accessed and referenced at anytime, anywhere, based on cognition, interpretation, analysis, and decision-making (Saad, 2011). Knowledge sharing is the social interaction and culture that involves the exchange, transformation and transfer of knowledge, skills and experience by each department or organization as a whole (Lim et al., 2010). It is linked to a broad perspective that is based on the exchange of all kinds of knowledge and includes implicit knowledge and explicit knowledge (Al-Tayeb, 2015).

The purpose of this study is to know the impact of TQM practices on employee performance. The modified role of knowledge sharing case study of Qatari Ministry of Interior, which leads to achieving some desired results, the most important of which is to build a culture in the organization to support the implementation of TQM, for the development of administrative thought, which proved its efficiency through which to overcome organization's problems related to the quality of services or productivity. The importance of study is to test its model and the results and recommendations of this study can be used by other ministries, which will contribute to development and improvement. 
The Ministry of Interior in Qatar provides services to its auditors around 24 hours, citizens and expatriates, requires employees to perform accurately and high level, and the performance problem of great importance to the ministry through working to optimize the human component, which necessitates the provision of employees with a high level and efficiency, as a result of enormous pressure on ministry, there is a significant fluctuation on employee performance, which may be due to the failure to apply quality management practices in the proper manner in ministry, and if these practices are properly implemented to ministry's superiority and permanent stability, knowledge and participation will play a major role in the creativity, excellence and full employee performance. Based on the above, the problem of study can be summed up in answering the following main question: How TQM practices influence on employee performance in presence of modified role of knowledge sharing in Ministry of Interior in Qatar.

\section{Literature Review}

\subsection{Total Quality Management and Employee Performance}

TQM seeks to create a distinct culture based on efforts of all members of organization to meet the customers' needs and their desires at the lowest cost, effort and time. This indicates that TQM has become importance to organizations through reducing costs, increasing profits and productivity, increasing customer satisfaction, achieving competitive advantage and high returns (Fernandes, 2017). The application of TQM in institutions is required to obtain some international quality certificates, to give the organization good reputation in eyes of external customers, as well as to develop a sense of unity of purpose, team spirit and mutual trust among individuals, in addition to enhancing the sense of belonging to the work environment (Zidane, 2010; Wann \& Shih 2004).

\subsubsection{Customer focus \& employee performance}

The essence of this concept is to satisfy customer with the required work properly from the first time, as well as to consider all employees to customers' focus of activity and attention, whatever the nature of their functions and employees must investigate reactions to customer on the services or products provided (Sugannthi \& Samuel, 2015). As the intended client is individual in which all activities and efforts are focused, in order to achieve or exceed his/her needs and expectations. Therefore, his/her current, future needs and desires must be determined (Boukmeish, 2010). It also includes dimensions of customer focus, identifying internal and external customers, knowing customer needs, desires, studying customer's trends, expectations, following up the complaints and taking the views when developing a product or service, and gaining new customers (Sugannthi \& Samuel, 2015). Therefore, organizations should identify their customers, study their needs and desires by following some means that enable organizations to reach this through personal interviews, questionnaires, establishing a system of suggestions, and ensuring participation by customer in quality teams (Juda, 2014).

The customer is one of most important pillars in which TQM is based. The researchers and authors have agreed to be focus on employees' activities and the top priority of TQM, from which to design operations, product and after sales services (Jabal, 2013). It is clear that the organization must work to increase efficiency of employees through training, studying, understanding the customers' needs and to use the special means to measure customer satisfaction, know the reasons for decline, rely on suggestions and opinions from customers about products that have been introduced and this will increase customer satisfaction and win new customers (Juma, 2007). There are many researchers and authors who agree on the importance of focusing on client in organizations where it has a positive impact on performance of employees and it is a key focus of any organization seeking to achieve the level of performance required of employees (Cai, 2009; Wu et al., 2004). 


\subsubsection{Continuous improvement and Employee performance}

Continuous improvement is defined as a philosophy to ensure the success and progress of organizations, which are based on attracting and retaining customers, providing all their requirements and needs, developing performance processes, as continuous improvement achieves profitability and competitive advantage and achieves objectives for successive success (Jonsdottir et al., 2014). Continuous improvement is a component of TQM to achieve customer satisfaction, it is one of sources that helps employees improve and differentiate from competitors, taking into account establishment of Organization's Quality Division, setting specific goals for quality improvement (Goetsch \& Davis, 2010). According to Aartsengel and Kurtoglu (2013) continuous improvement is a mechanism to shift direction of work for better performance in the short term and to maintain gains and increase long-term returns by building on customer satisfaction, improving staff capabilities and skills, continuous improvement requires that improvement be a sincere and lasting desire in organization and be managed towards a gradual improvement in all processes and at all levels by providing employees with necessary skills, preparing training courses, encouraging staff to work together and participate because continuous improvement is the responsibility of everyone (Jacobson et al., 2009). One of the most important entrances to continuous improvement (the introduction of Deming cycle) is one of main pillars affecting the performance of employees, through which it can achieve significant improvements in their operations, contribute to improve their performance and achieve the highest level of customer satisfaction (Aishouni, 2009). Through research studies, Dodi (2014) noted that training and motivating workers: increases performance, increases employee productivity, reduces error rates, and makes employees feel more stable and more useful.

\subsubsection{Employee Participation and Employee performance}

(TQM) defined as working environment in which worker obtains the ability, trust and commitment to improve productivity, meet the needs and desires of the clients, to achieve objectives and values of organization (Obeidat et al., 2018; Besterfield et al., 2014). TQM practices require decisions to delegate to average and operational level, the process of delegating and involving staff to make decisions about their tasks is a good motivational method, as well as sensitizing them to decisions they make (Juda, 2014). Therefore, the participation of employees is one of main needs of success of TQM. It works to implement participatory strategies to enhance the cooperative performance of employees and to document their participation with the managers on the other hand in decision-making processes to achieve the goals of organizations (Sharma et al., 2014). According to Al-Dardaka (2001) TQM is important for participation of employees in getting their services. Quality management principles are responsibility of all employees in organization. Therefore, they strive to promote collective work, encourage, achieve continuous improvement, and build a greater contribution to solve, productive and operational problems among different employees. The participation of staff in efficiency of organization will increase its production by motivating employees to participate in setting objectives and making greater use of this participation in meeting the challenges of market (Titi, 2010). Ahire and Dreyfus (2000) added that people responsible for employee performance are those who are keen to participate and contribute to continuous improvement as participation of employees leads to a frank discussion of problems, issues and responsibilities with people within organization to resolve them, and their understanding of importance of their contribution and their role in innovation and creativity in promoting the objectives of organization.

\subsubsection{Leadership \& good vision \& Employee performance}

Leadership includes the belief and conviction of senior management that organization can benefit from its implementation of TQM system, and it must provide necessary resources and train staff in quality management methods and methodologies (Moussa \& Shazly, 2012). Leaders must identify vision, trends, high expectations, and values (Baldrige National Quality Program, 2014). One of the reasons for the success of the application of TQM is associated with the support received from senior management and adoption of philosophy of quality management in all activities and operations carried out, and the 
ability to convince and influence employees, the commitment of leadership is to strengthen the culture of quality and improve capabilities of staff in performance of functions and tasks (Hammoud, 2012), and to ensure the success of TQM, which requires senior management strong commitment to its principles (Riggs, 2014). Alimat (2004) noted the importance of leadership role is in achieving TQM by giving employees' confidence, reducing the number of administrative, supervisory levels and changing traditional role of management from police supervision to guidance and training as well as making quality primarily for all administrative and technical activities. The commitment of senior management to total quality management requires leadership to train basic concepts of philosophy of quality management in order to benefit from its advantages, allocate necessary resources and make changes to achieve the success of TQM and improve performance of employees within them through rewards and training (Fadlallah, 2015):

\subsubsection{Operations Management \&Employee Performance}

The process is a set of interrelated activities that transform inputs into outputs. In order for organization to achieve a high level of quality in products or services, it may require full or partial redesign of processes to align operations with the requirements (Juda, 2014), it covers all processes in the organization that contribute to quality of product or service, as well as in a manner that prevents errors (Bukhmish, 2010). This means bypassing the emphasis on outputs only, focusing and caring for processes because sound processes ensure that we have healthy outputs (Al-Aeshy, 2012). The improvement of operations involves the ability of organization to analyze the activities required to provide service, eliminate activities and lost work cycles that add no value to product or service, streamline procedures, reduce the number of steps to provide the service, move from sequential operations to concurrent operations, reduce the time of transfer from one department to another as a measure to reduce the time required to provide service (Barakat, 2007). The Operations Management provides skill and professionalism, and includes work procedures and practices through the competencies and experience of workers, which develops business practices and increases the interdependence of individual performance (Buck, 1999). Innovation in management of operations is achieved through the contribution of employees in production of innovative solutions to problems, as well as the development and support of innovation processes in organization (Titi, 2010).According to Brun (2010), the application of TQM practices, including process management, has an impact on employee performance and directly affects organization's performance.

\subsection{Knowledge Sharing and employee performance}

Knowledge sharing affects the employees of the organization in different ways. First, knowledge sharing enhances learning, and makes use of their learning. Such learning allows the organization to grow and become capable of making changes. The second is the process of sharing knowledge by making employees more flexible and supporting their work satisfaction, which means helping employees build their learning abilities to address and solve various problems facing organization's activities (Titi, 2010). According to Oakland (2005), staff in organization can be involved in identifying limitations of their performance and evaluating their performance against group in order to enhance their competence and freely share experience and knowledge. The involvement of employees means knowledge sharing and enhances their contribution to creativity, innovation and problem solving within the organization.

Sharing knowledge is to achieve the desired performance through the generation, storage, distribution and application of useful knowledge facilitates work within organization, leading to creativity and innovation, introducing new things and increasing cultural awareness among employees through training, learning and dialogue (Titi, 2010). Abdul hafiz et al. (2015) pointed out that there is an urgent need to share knowledge in organizations to support their creative and competitive capabilities. Knowledge sharing is also important at the individual or personal level in terms of supporting human ties and relationships among colleagues, the importance of knowledge sharing at the individual and organizational levels 
emphasized at the individual level. The importance of individual knowledge sharing is in helping individuals to perform their functions more effectively, helping them to stay in their jobs, promoting career advancement and personal development, and a sense of satisfaction for employees because of their contribution to their personal knowledge. The organizational importance of knowledge sharing reflected in increased efficiency improvement, reduced training costs and reduced risk of uncertainty.

The importance of sharing knowledge is the desire of organizations to achieve quality and excellence in their operations and outputs, and the increasing development in work-related education, as well as the availability of knowledge makers from universities, as a center of attracting professors and students of science and researchers. One of natural requirements that students seek to reach by joining universities is to acquire knowledge (Al-Othman, 2013). This highlights the importance of knowledge sharing through the rotation of knowledge among all individuals to ensure their survival and continuity in organization (Gurteen, 2012).

\section{Research Methodology}

\subsection{Research Model and Hypotheses}

In order to achieve the objectives of the study, the researchers used an analytical descriptive approach to describe the phenomenon studied. A questionnaire was designed to measure the independent variables represented by the dimensions of TQM practices, where the dependent variable is employee performance, through the mediated variable of knowledge sharing. The study tries to find the relationship between the variables of the study, analysis and interpretation in order to reach meaningful generalizations increases and enriches the stock of knowledge on the subject, and build interpretations of data and information in order to obtain the desired results. In order to test the impact of TQM practices on employee performance and the mediated role of knowledge sharing, the following hypotheses were developed:

$\mathrm{H}_{1}$ : TQM practices (customer focus, continuous improvement, process management, employee participation, leadership and good vision) influences on employee performance.

$\mathrm{H}_{2}$ : TQM practices (customer focus, continuous improvement, process management, employee participation, leadership and good vision) influences on employee performance through sharing knowledge.

The Research Model

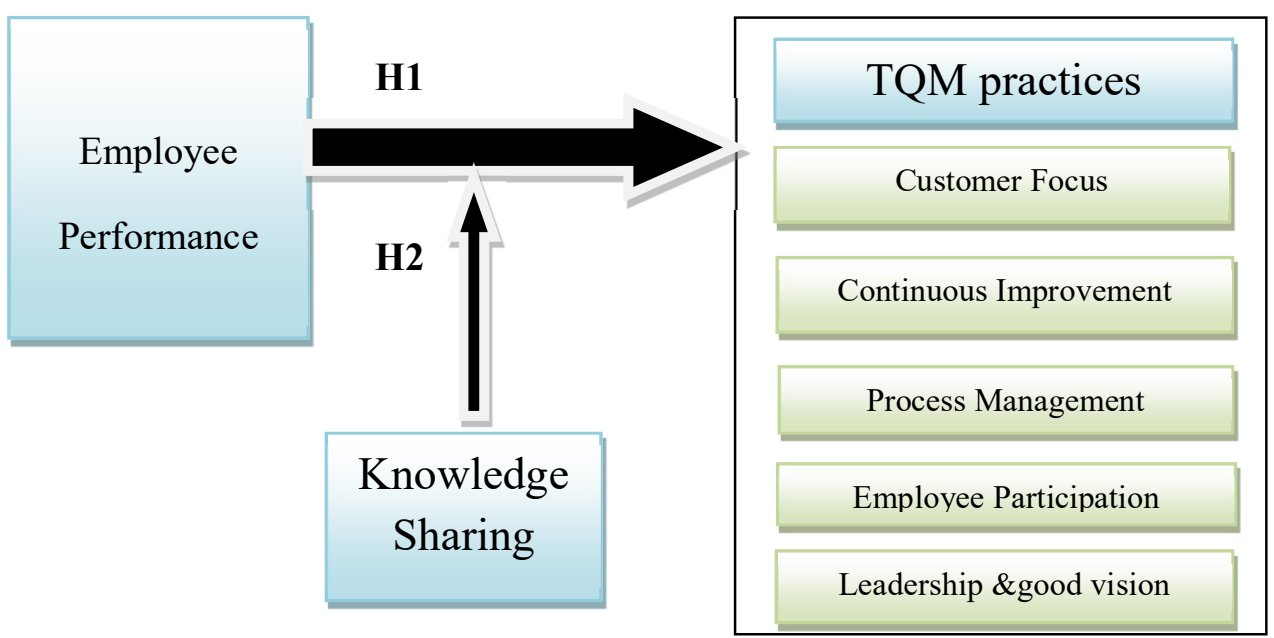

Fig. 1. The proposed study 


\subsection{Society and sample study}

The study community includes the staff of Ministry of Interior in Qatar. The researchers submitted a request to the Human Resources Department (HRD) to approve the study, and they did. Human resources department has identified (5) departments for the study, shown in Table 1. There were 1355 employees in those department at various administrative levels. The sample size was determined by the Sekran statistical tables (Sekaran, 2013), where the number of random samples was determined to 300 employees, and the sample was distributed proportionate to the concerned departments. The researcher distributed (300) questionnaires to the sample of the study and a total of 291 questionnaires were retrieved, in which 11 were useless.

Table 1

Study \& sample population

\begin{tabular}{llcc}
\hline No & Department & Number of employees & Sample \\
\hline 1 & Telecommunications & 400 & 88 \\
2 & Planning \& Quality & 90 & 20 \\
3 & Human Rights & 30 & 7 \\
4 & Medical Services & 790 & 175 \\
5 & Police Training & 45 & 300 \\
\hline Total & & 1355 & \\
\hline
\end{tabular}

\subsection{Study tool}

In this study, the researchers relied on the use of descriptive analytical methodology, which stems from the study of research organization and the method of field study and the questionnaire included two parts: the first includes general information for respondents, the second includes a set of paragraphs and phrases that reflect the questions, objectives, variables and hypotheses of study, (TQM practices, employee performance, sharing of knowledge), to be answered by members of study sample. The questionnaire was followed by the Likert measurement method based on the (Likert) scale pentacle to determine the weights of paragraphs assigned to measure each variable of study, where these weights determine the trends of the sample members towards each of paragraphs of the variable, to determine the general level of variable and the relative importance of paragraphs and variables. The five-point Likert scale, which starts from strongly approved (5), is so strongly disapproved (1)

\section{Research Results}

\subsection{Validity and Reliability}

The authentic honesty of questionnaire was tested by presenting it as arbitrators with the expertise and competence of academic professors, in order to express an opinion regarding their validity to collect data on study, its clarity, coherence, The observations and suggestions of the arbitrators were taken into account, the instrument of the study was validated for measuring what was designed for it. The stability of the instrument used to measure variables included in the (Cronbach Alpha Coefficient) test, where the result of scale is statistically acceptable if the value of Cronbach Alpha is greater than (0.60) (Sekaran, 2013). In view of the data in following table, the coefficient of internal consistency of the Cronbach was measured to find out the consistency of the answers. Table 2 demonstrates the results of our survey.

\section{Table 2}

Internal consistency coefficient values for the study tool paragraphs

\begin{tabular}{llllll}
\hline NO & Dimension & Alpha value & NO & Dimension & Alpha value \\
\hline 1 & Customer focus & 0.825 & 5 & Process management & 0.884 \\
2 & Continuous improvement & 0.888 & Total quality management practices & 0.959 \\
3 & Employee participation & 0.914 & 6 & Performance of employees & 0.862 \\
4 & Leadership and good vision & 0.864 & 7 & Sharing knowledge & 0.915 \\
\hline TOTAL & 0.970 & & &
\end{tabular}




\subsection{Description of study sample characteristics}

This section includes a description of demographic variables of study the sample members: (Gender, age, Education, Experience, and Position). in order to describe the characteristics of sample study, the frequency of demographic variables are found in Fig. 2 as follows,

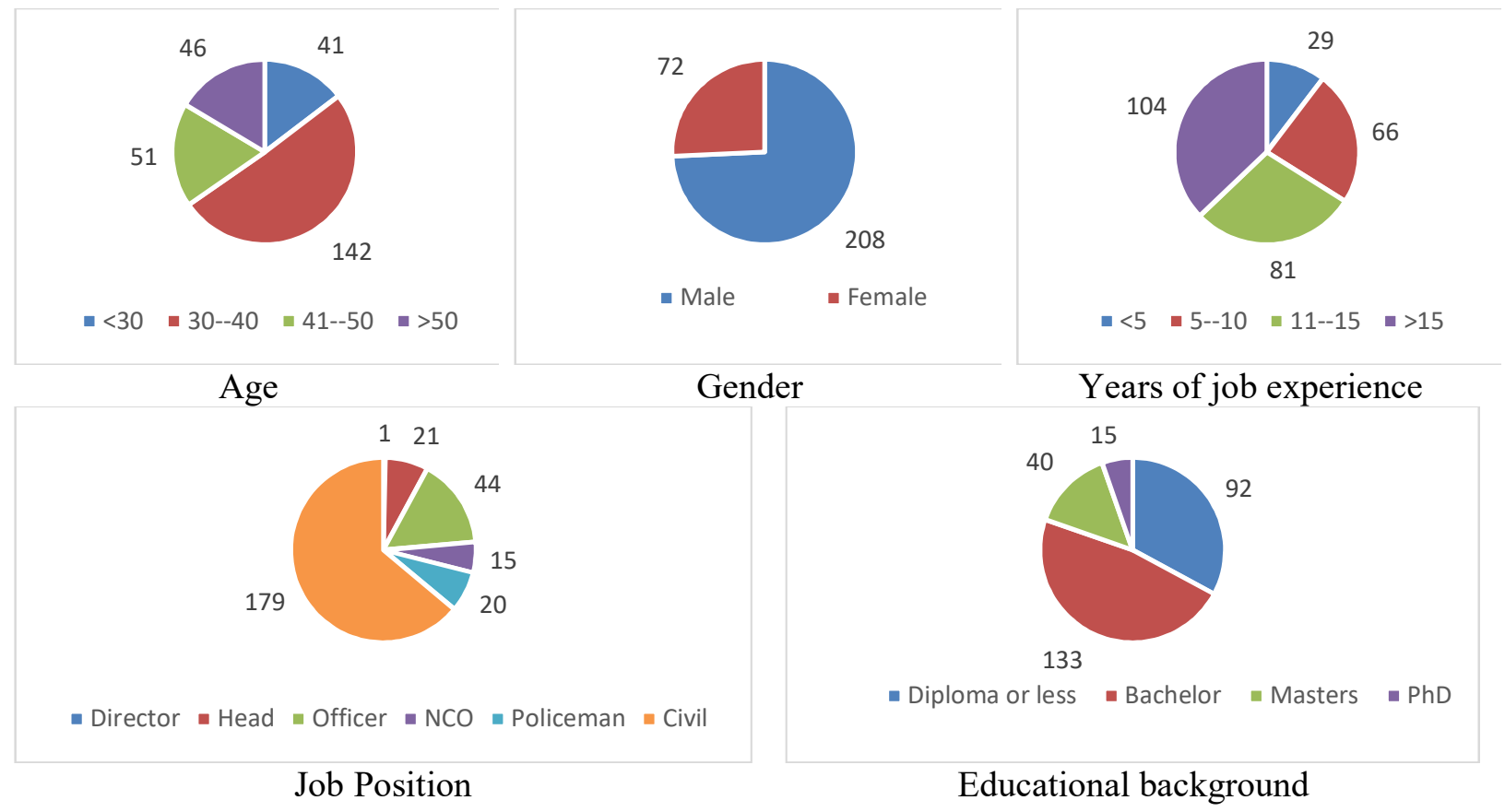

Fig. 2. Demographic profile of survey respondents

\subsection{Descriptive Statistics}

Table 3 demonstrates some basic statistics associated with the variables of the proposed method.

Table 3

The arithmetic mean, standard deviations, rank and relative importance of the variables

\begin{tabular}{|c|c|c|c|c|c|}
\hline Type of variable & Variables & Average & $\begin{array}{l}\text { Standard } \\
\text { deviation }\end{array}$ & Rank & Level \\
\hline \multirow{6}{*}{ Independent variables } & Customer focus & 4.175 & 0.766 & 3 & high \\
\hline & Continuous Improvement & 4.379 & 0.717 & 1 & high \\
\hline & Employee Participation & 4.129 & 0.845 & 5 & high \\
\hline & Leadership and good vision & 4.155 & 0.776 & 4 & high \\
\hline & Process Management & 4.301 & 0.655 & 2 & high \\
\hline & Total quality management practices & 4.288 & 0.662 & & high \\
\hline \multirow{2}{*}{$\begin{array}{l}\text { Dependent variables } \\
\text { Moderating Role }\end{array}$} & Performance of Employees & 4.546 & 0.466 & & high \\
\hline & Sharing knowledge & 3.971 & 0.703 & & high \\
\hline
\end{tabular}

According to Table 3, we note that the overall average of TQM practices in terms of relative importance is high, with a general average of (4.228) and a standard deviation of (0.662). Continuous improvement was ranked first with an average of (4.379) and a standard deviation of (0.717) and a high relative importance, while the follow-up (follow-up employees) was ranked last with an average of (4.129) and a standard deviation of (0.845) and a high relative importance. This may be due to the behavior of senior management of Ministry of Interior in Qatar towards the implementation of TQM in all departments of Ministry. An occupation after the (last-minute participation of employees) may be to fact that the participation is in accordance with administrative hierarchy (Organizational Structure) in departments of Ministry. We also note from above table that the general arithmetic average of employee performance points 
in terms of relative importance yields a high value of (4.546) and a standard deviation of (0.466). We also note from the above table that the general arithmetic means of knowledge sharing paragraphs in terms of relative importance is high with (3.971) and a standard deviation of (0.703).

\subsection{Hypotheses Testing Results}

\subsubsection{The first hypothesis}

To test the first hypothesis, multiple regression analysis was used. The results were as follows:

Table 4

The results of the effect of TQM practices on employee performance $(\alpha=5 \%)$

\begin{tabular}{lcccc}
\hline Variables & $\mathrm{B}$ & Standard Error & $\mathrm{T}$ & Sig t* \\
\hline Customer Focus & 0.003 & 0.038 & 0.065 & 0.948 \\
Continuous Improvement & 0.119 & 0.051 & 2.347 & 0.020 \\
Employee Participation & 0.144 & 0.039 & 3.666 & 0.000 \\
Leadership and good vision & 0.041 & 0.053 & 0.779 & 0.437 \\
Process Management & 0.215 & 0.048 & 4.503 & 0.000 \\
\hline
\end{tabular}

$\mathrm{R}=0.727 \mathrm{R}^{2}=0.529 \mathrm{~F}=61.471(0.000)$ (Dependent variable: Employee performance)

Table 4 shows that the correlation coefficient is $(\mathrm{R}=0.727)$ which is associated with the relationship between independent and dependent variables. The $\mathrm{F}$ value (61.471) is statistically meaningful when the level of significance is one percent and the value of coefficient of determination $\left(\mathbf{R}^{\mathbf{2}}=0.529\right)$ indicates that $(52.9 \%)$ of variation in (Employee Performance) can be explained by the variation in TQM combined. The table of coefficients showed that the value of B at the end (the focus on the client) reached (0.003) with the $\mathrm{t}$ value of $(0.065)$ ( $\mathrm{Sig}=0.948)$, which indicates that the effect of this dimension is insignificant. The value of B at a time (Continuous Improvement) reached ( 0.119$)$ with t-value of (2.347, $\mathrm{Sig}=0.020)$, which indicates that the effect of this dimension is significant. The value of $\mathrm{B}$ at the time (Employee Participation) is equal to $(0.144)$ with $(t=3.666 \mathrm{Sig}=0.000)$, which indicates that the effect of this dimension is significant. The value of B at the distance (Leadership \& good vision) is equal to 0.041 with $(\mathrm{t}=0.779, \mathrm{Sig}=0.437)$, which indicates that the effect of dimension is insignificant. The value of $\mathrm{B}$ at a time (Operations Management) is equal to 0.215 with $(\mathrm{t}=4.503, \mathrm{Sig}=0.000)$, indicating that the effect of dimension is significant. To determine which dimensions of TQM practices had the most significant impact on staff performance, the gradient regression analysis was used (See Table 5).

\section{Table 5}

The results of the regression analysis for the first main hypothesis $(\alpha \leq 0.05)$

\begin{tabular}{llllcccc}
\hline Model & Performance of Employees & B & t-value & Sig* & R2 & F & Sig* \\
\hline \multirow{2}{*}{ First } & Process Management & 0.469 & 14.604 & 0.000 & 0.434 & 213.266 & 0.000 \\
\hline \multirow{2}{*}{ Third } & Process Management & 0.290 & 7.200 & 0.000 & \multirow{2}{*}{0.511} & \multirow{2}{*}{144.832} & \multirow{2}{*}{0.000} \\
& Employee Participation & 0.207 & 6.608 & 0.000 & & & \multirow{2}{*}{0.000} \\
& Process Management & 0.226 & 5.025 & 0.000 & \multirow{2}{*}{0.528} & \multirow{2}{*}{102.766} & \\
& Employee Participation & 0.156 & 4.475 & 0.000 & & & \\
& Continuous Improvement & 0.137 & 3.102 & 0.002 & & &
\end{tabular}

The results of the regression analysis show the order of entry of the variables in the regression model that represents the impact of TQM practices on employee performance, it was found that (Operations Management) came in first place, and explained $43.4 \%$ of the changes in the dependent variable, while we add (Employee Participation) in the second model, the interpretation rate increased to $(51.1 \%)$, the addition of (Continuous Improvement) has led to an increase in interpretation rate to $(52.8 \%)$. We note that the effect of all independent variables had significant effects at a level of significance less than 0.05 , with the exception of dimension (Customer Focus, Leadership \& good vision).

\subsubsection{The second hypothesis}

In order to test the second hypothesis, the Hierarchical regression analysis was used, and the results were as follows: 
Table 6

The results of the Hierarchical regression $(\alpha \leq 0.05)$

\begin{tabular}{|c|c|c|c|c|c|c|c|}
\hline \multirow{2}{*}{$\begin{array}{l}\text { Dependent } \\
\text { variables }\end{array}$} & \multirow[t]{2}{*}{ Independent variables } & \multicolumn{3}{|c|}{ First step } & \multicolumn{3}{|c|}{ Second step } \\
\hline & & B & t-value & Sig t & B & t-value & Sig t \\
\hline \multirow{10}{*}{$\begin{array}{l}\text { Employees } \\
\text { Performance }\end{array}$} & Customer focus & 0.003 & 0.065 & 0.948 & 0.021 & 0.555 & 0.579 \\
\hline & Continuous Improvement & 0.119 & 2.347 & 0.020 & 0.110 & 2.206 & 0028 \\
\hline & Employee Participation & 0.144 & 3.666 & 0.000 & 0.084 & 1.985 & 0.048 \\
\hline & Leadership and good vision & 0.041 & 0.779 & 0.437 & 0.027 & 0.524 & 0.600 \\
\hline & Process Management & 0.215 & 4.503 & 0.000 & 0.163 & 3.304 & 0.001 \\
\hline & Sharing knowledge & & & & 0.174 & 3.445 & 0.001 \\
\hline & $\mathrm{R}^{2}$ & \multicolumn{3}{|c|}{0.529} & \multicolumn{3}{|c|}{0.548} \\
\hline & $\Delta \mathrm{R}^{2}$ & \multicolumn{3}{|c|}{0.529} & \multicolumn{3}{|c|}{0.020} \\
\hline & $\Delta \mathrm{F}$ & \multicolumn{3}{|c|}{61.471} & \multicolumn{3}{|c|}{11.865} \\
\hline & $\operatorname{Sig} \Delta \mathrm{F}$ & \multicolumn{3}{|c|}{0.000} & \multicolumn{3}{|c|}{0.001} \\
\hline
\end{tabular}

Table 6 show the results of two-model hierarchical regression, the results of first model are based on first step reflected a statistically significant impact of the dimensions of (TQM) Combined on employees performance, where the value of $\Delta \mathrm{F}=61.471$ and significance level (Sig $\Delta \mathrm{F}=0.000$ ) indicate the relationship is statistically significant. Also, the value of coefficient of determination is $\left(\mathbf{R}^{2}=0.529\right)$, which indicates that the dimensions of (total quality management practices) combined account for $52.9 \%$ of the variation in employee performance.

In the second step, a variable (Knowledge Sharing) was introduced to regression model, where the value of $\mathbf{R}^{2}$ was increased by (2.0\%), this is a statistical function, where the value of ( $\left.\Delta \mathrm{F}=11.865\right)$, at a level of significance ( $\operatorname{Sig} \Delta \mathrm{F}=0.001)$, it is less than 0.05 , the value of $(\mathrm{B}=0.174)$ at (sharing knowledge) (Sig $\mathrm{t}=0.001$ ). This confirms the difference in moral impact of dimensions of TQM practices on employee performance through knowledge sharing.

\section{Discussion and conclusion}

The aim of this study was to know the effect of TQM practices on employee performance. The modified role of knowledge sharing for the case study of Ministry of Interior in Qatar, where the results of analysis of study tool have shown the relative importance of TQM practices in Qatari Ministry of Interior, after Continuous Improvement was ranked first and Employee Participation was ranked last. This indicates the high level of senior management for total quality culture, and its interest in spreading this culture throughout the Ministry, documenting the work procedures, achieving flexibility and making the necessary improvements. As for the variable performance of employee has been the relative importance of a high level, this may be due to policies and procedures adopted by the ministry in dealing with staff and provide adequate support for them, and to work to meet their needs and requirements of incentives and rewards, social requirements, and to raise the level of their professional and practical performance by providing different training courses and encouraging them to participate in it, which motivates them to perform the work and accomplish the tasks entrusted to them as desired, required, the highest levels of efficiency and skill, in addition to the implementation of an annual performance evaluation system of highest efficiency. Finally, the results of analysis of the study have shown the relative importance of knowledge sharing in Qatari Ministry of Interior and this may be due to Ministry's interest in attracting the owners of expertise, skills and high competencies to work for them, and benefit from them through their integration into the work, provide channels of communication and interaction between them and personnel working in various departments of ministry through holding of seminars and workshops, in addition to holding of periodic meetings ongoing through electronic means (video meetings), and participate in project management related to planning and organization. The results of the first hypothesis have shown that TQM practices influenced on employees performance, where the moral impact was shown in both (Continuous Improvement, Employee Participation, and Operations Management), while the impact did not appear at all for some other components (i.e. Customer Focus, leadership and good vision), this does not negate importance of these dimensions. The findings are consistent with the results of Mohamed 
(2017), which reached a direct intermediate link between the conviction of senior management of application of TQM and performance. It also concurred with the results of Al Muamer (2014) who found a strong relationship with the four TQM domains individually and combined with functional performance. The results are also consistent with the results of Abu Ziada (2011) who found the impact of dimensions of TQM combined on organizational performance related to performance of human resources.

The results of present study were consistent with results of study accomplished by Zhang et al. (2016), which found a positive relationship between quality management practices and innovative performance. In addition, the results of Ardestani and Amirzadeh (2014) are in line with our results, wher they found a statistically significant relationship between total quality management practices and organizational performance. It also concurred with results of study accomplished by Sawaluddin et al. (2013) that concluded that the implementation of quality management practices based on Baldrige model standards, had a very positive impact on overall performance. The results of gradual regression analysis have shown that operations management is the most influential on employee performance. This may be due to the fact that operations department is the specialty of employees of Ministry of Interior, and the help of modern technological systems. The results of the second hypothesis showed a statistically significant impact of TQM practices (customer focus, continuous improvement, employee participation, leadership, and process management) on employee performance in sharing knowledge, which can be attributed to fact that knowledge sharing contributes to exchange of knowledge and experience among employees. The establishment of databases that have a high capacity to store and retrieve data and information helps achieve the objectives of TQM and improve employee performance, and agreed with results of study (Hassan al-Tayeb, 2015), which found a significant statistical impact of knowledge sharing on the performance of human resources, a positive impact of knowledge sharing on human resource productivity at work, the quality of human resources work, and behavioral side of human resources performance, and also coincided with results of study by Huang (2010) who found that there is a role of participatory knowledge through the transfer of individuals in development of new products and reflected in the overall performance levels.

\section{Implications and Future Research}

The study has been accomplished based on the relevant published studies. The researchers developed a model to study the impact of TQM practices on employee performance: the modified role of knowledge sharing and a review of previous literature shows that similar studies have not been conducted in State of Qatar. In addition, the results of this study may seem useful to Qatari Ministry of Interior and other ministries in terms of developing and implementing different strategic directions to enhance performance of their employees, through attracting qualified and specialized human cadres to fill shortage in some departments and reduce volume of work pressure on staff, which contributes to the completion of work on time and reduce errors of work, as well as to provide opportunities for employees in Ministry to participate in development of plans and objectives that achieve the strategies of departments of Ministry. The activation and implementation of controls and conditions in which the system of material and moral incentives in ministry, and dissemination to all employees, in addition to providing specialized communication channels between individuals working in ministry, which allows exchange of knowledge and experience and sharing, in order to increase the level of interest in taking into account all aspects of preventive work performance, which is commensurate with the nature and functions of each department, which reflects positively on employee performance.

\section{References}

Aartsengel, A. V., \& Kurtoglu, S. (2013). A Guide to Continuous Improvement Transformation: Concepts, Processes, Implementation. 
Abdul Hafiz, T., Abdul Hamid, Y., \& Fathi Alhendawi, M. (2015). The reality of the practice of knowledge sharing among faculty members, an applied study on the faculties of education in some Arab universities. Journal of Educational and Psychological Sciences, 16, Al Qussaim university.

Abu Sultan, M. (2011). Functional expatriation and its relation to job performance of employees in Ministry of Education and Higher Education in the Gaza Strip. Unpublished Master Thesis, Islamic University, Gaza.

Aeeshe, A. (2012). Training Trends and Performance Assessment. Individuals, Osama Publishing House, Amman, Jordan.

Ahire, S. L., \& Dreyfus, P. (2000). The impact of design management and process management on quality: an empirical investigation. Journal of Operations Management, 18(5), 549-575.

Aishouni, M. A. (2009). TQM as a methodology for improving performance in the government sector. The International Conference on Administrative Development, towards outstanding performance in the government sector, Riyadh.

Al Muamer, W. (2014). The relationship of total quality with the performance of employees in the Palestinian universities Gaza Strip, unpublished Master Thesis, Al-Azhar University.

Ali, A. (2010). Human resources development in light of the application of the principles of total quality management in universities. International Islamic University. Malaysia.

Alimat, S.N. (2004). Total Quality Management in Educational Institutions. Dar Al Shorouq, Amman, Jordan.

Al-Othman, A.B.M.A.A. (2013). the reality of the application of knowledge management at Naif Arab University for Security Sciences: obstacles and ways of development. Master Thesis (Graduate School, Department of Administrative Sciences.

Al-Samurai, B. (2012). The role of leadership in applying the principles and principles of comprehensive quality management (unpublished Master thesis). Britch Arab Academic

Alwan, K. (2013). Total Quality Management and ISO 9001: 2000. Amman. Dar Al Thakafa for Publishing \& Distribution.

Al-Zu'bi, A. (2013). The role of total quality management in reducing risks in the Jordanian higher education sector in the context of the global economic crisis (Applied Study). The Arab Journal for Quality Assurance of Higher Education, 6(11) 3-39.

Ardestani, A., \& Amirzadeh, Y. (2014). The impact of total quality management practices on innovation performance and organizational performance. Indian Journal of Fundamental and Applied Life Sciences 4(4), 2050-2057.

Baldrige National Quality Program (2014). CRITERIA for Performance Excellence, National Institute of Standards and Technology, United States: Department of Commerce.

Barakat, M. (2007). The reality of the application of TQM under the Organizations culture in the Gaza Strip. A magister message that not published. Islamic University, Gaza, Palestine.

Bartoli, A. (1997). Le managementdans L organization publique. edition Dunod, Paris.

Besterfield, D.H., Michna, C.B., Besterfield, G.H., \& Sacre, M.B. (2014). Total Quality Management. USA: Pearson Education.

Boukmeish, A. (2010). Total Quality Management ISO - 9000. Al - Raya Publishing, Amman.

Brun, A. (2011). Critical success factors of Six Sigma implementations in Italian companies. International Journal of Production Economics, 131(1), 158-164.

Buck, J. Y. (1999). Le management des connaissances. Mettreen oeuvre un project de Knowledge Management, Paris, Editions Organization, 207 p.148.

Cai, S. (2009). The importance of customer focus for organizational performance: a study of Chinese companies. International Journal of Quality \& Reliability Management, 26(4), 369-379.

Salami, C. G. E., \& Ufoma Akpobire, O. (2013). Application of total quality management to the Nigerian education system. Global Advanced Research Journal of Educational Research and Review, 2(5), 105-110.

Dawoud, A.A. (2010). Quality management \& academic accreditation. For Publishing and Distribution, Amman, Jordan. 
Dodi, A.Y. (2014). Total Quality Management. Academies for Publishing and Distribution, Amman, Jordan.

Al-Ffadi, S. (2008). Working teams and their relationship to the performance of employees in the security services - a comparative study between the devices in Riyadh. Unpublished PHD thesis. Prince Naif Arab University for Security Sciences, Riyadh.

Fadlallah, A. O. (2015). The impact of total quality management on the performance of employees in service organizations. Master's Thesis in Business Administration, Faculty of Graduate Studies, Shandi University, Sudan.

Fernandes, A. C., Sampaio, P., Sameiro, M., \& Truong, H. Q. (2017). Supply chain management and quality management integration: A conceptual model proposal. International Journal of Quality \& Reliability Management, 34(1), 53-67.

Goetsch, D.L., \& Davis, S.B. (2010). Quality management for organizational excellence. New Jersey: USA Pearson Education

Gurteen, D. (2012). Leading issues in social knowledge management. Academic Conferences Limited.

Hariri, (2016). Total quality in curriculum and teaching methods. Amman: Dar Al Masirah.

Jacobson, G. H., McCoin, N. S., Lescallette, R., Russ, S., \& Slovis, C. M. (2009). Kaizen: a method of process improvement in the emergency department. Academic emergency medicine, 16(12), 13411349.

Jonsdottir, S., Ingason, H. T., \& Jonasson, H. I. (2014). Continuous improvement projects in certified organizations in Iceland: traditional projects or not?. Procedia-Social and Behavioral Sciences, 119, 142-151.

Juda, M.A. (2014). Total Quality Management Concepts and Applications. Dar Wael Publishing. Oman. Jordan.

Juma, H. (2007). Quality \& Relationship with Suppliers and Clients. Third International Conference on Quality and Excellence in Business Organizations, Faculty of Economic Sciences and Management Sciences, Skikda University, Algeria, 7-8 May.

Li, J., \& Houjun, Y. (2013). Towards a frame work of quality management for cooperative higher education. In 2013 the International Conference on Education Technology and Information System (ICETIS 2013). Atlantis Press.

Mahasneh, I. (2013). Management \& evaluation of functional performance between theory and practice. I. Dar Jarir for Publishing and Distribution. Oman. Jordan.

Malkawi, N., Obeidat, A. M., \& Halasa, A. (2017). Achieving Performance Excellence through Cloud Computing Atmosphere-Applied Study at Zain Telecommunications Company-Jordan. International Review of Management and Business Research, 6(1), 229-243.

Oakland, J. (2005). From Quality to excellence in 21st century. Total Quality Management, 16(8-9), 1053-1060.

Obeidat, A. M., Abualoush, S. H., Irtaimeh, H. J., Khaddam, A. A., \& Bataineh, K. A. (2018). The role of organisational culture in enhancing the human capital applied study on the social security corporation. International Journal of Learning and Intellectual Capital, 15(3), 258-276.

Qureshi, M. (2011). External Resources Operations as an Approach to Improving the Performance of the Economic Corporation. Intervention at the Second International Symposium on Outstanding Performance of Government Organizations, University of Ouargla, November 22-23.

Saeed, R., Mussawar, S., Lodhi, R. N., Iqbal, A., Nayab, H. H., \& Yaseen, S. (2013). Factors affecting the performance of employees at work place in the banking sector of pakistan. Middle-East Journal of Scientific Research, 17(9), 1200-1208.

Riggs, D.E. (2014). Strategic quality management in libraries. Englewood, CO. A Sourcebook, Libraries Unlimited.

Saad, M.M.I. (2011). Knowledge management practices of university leaders, applied study on the University of Alexandria. Studies in University Education - Egypt, 23, 91-192.

Sadikoglu, E., \& Olcay, H. (2014). The effects of total quality management practices on performance and the reasons of and the barriers to TQM practices in Turkey. Advances in Decision Sciences, 2014. 
Salajegheh, S., \& Pourrashidi, R. (2013). The Relationship Between Total Quality Management (TQM) and Organizational Performance. Interdisciplinary Journal Of Contemporary Research In Business, 5(4), 478-489.

Sawaluddin, A., Surachman, R., Djumahi, M. \& MintartiRahayu, D. (2013). Quality management practices of Malcom Baldrige National Quality Award (MBNQA) studies at college in south east Sulawesi, Indonesia. International Journal of Business Management Invention, 2(11), 11-25.

Sekaran, U. (2013). Research methods for business. Hoboken, NJ: John Wiley \& Sons.

Sharma, K. S., Gupta, S. V., \& Singh, R. (2014). Implementation of TQM for improving organizational effectiveness. International Journal of Application or Innovation in Engineering \& Management (IJAIEM), 3(9).

Sugannthi, L. \& Samuel, A.A. (2015). Total Quality Management. New Delhi: Asoke K. Ghosh, PHI Learning Private Limited.

Taleghani, M., Akhlagh, E. M., \& Hoseini, A. (2013). The effect of total quality management (TQM) on organization performance the mediation of market orientation. Interdisciplinary Journal of Contemporary Research in Business, 5(6), 627-239.

Titi, K.M. (2010). Knowledge Management: Challenges, Techniques. Dar Al-Hamed Publishing and Distribution.

Wu, W. Y., Hsiao, S. W., \& Kuo, H. P. (2004). Fuzzy set theory based decision model for determining market position and developing strategy for hospital service quality. Total Quality Management \& Business Excellence, 15(4), 439-456.

Zhang, Q., Feng, X., \& Xiang, X. (2016). The Impact of Quality Management Practices on Innovation in China: The Moderating Effects of Market Turbulence. American Journal of Industrial and Business Management, 6(03), 291.

Zidane, S. (2010). TQM philosophy and work approaches. Amman: Dar Al Manaheg for Publishing and Distribution.

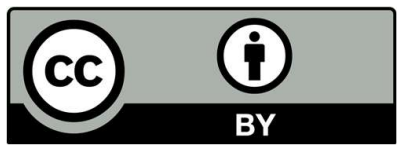

(C) 2020 by the authors; licensee Growing Science, Canada. This is an open access article distributed under the terms and conditions of the Creative Commons Attribution (CCBY) license (http://creativecommons.org/licenses/by/4.0/). 